\title{
Estudo das influências socialmente construídas no desempenho escolar
}

\author{
Isabella Ferreira Cardoso \\ João Alberto da Silva \\ Crislaine de Anunciação Roveda
}

\section{Resumo}

O artigo apresenta um estudo sobre influências socialmente construídas no desempenho escolar amparado em pesquisa realizada com professoras dos terceiros anos do ciclo I de Ensino Fundamental. A pesquisa busca principalmente, analisar como o processo avaliativo se constitui com o decorrer do desenvolvimento de desempenho escolar dos alunos, considerando as influências sociais que interpelam o cotidiano nas salas de aulas e se entrecruzam nos afazeres e nas atribuições curricular escolares. Utilizando-se da técnica metodológica de Análise Textual Discursiva (MORAES \& GALIAZZI, 2011) foi possível chegar a duas categorias de análise: práticas pedagógicas e as inferências no desempenho escolar e influências socialmente construídas sobre desempenho escolar. A primeira categoria abarca as principais questões entorno da referência a processos avaliativos e metodológicos. A segunda apresenta reflexões sobre questões familiares e afetivas que interpelam o cotidiano escolar. Conclui-se que a compreensão de como os mecanismos extracurriculares sociais influenciam a percepção de desempenho escolar de alunos, decorrente do que é apresentado por pesquisa sobre processos avaliativos, ocorre de modo muito variado e particular de cada professora entrevistada, devido as variadas formas de atuação e formação.

Palavras chave: Avaliação Formativa; Desempenho escolar; Influências sociais; anos iniciais de Ensino Fundamental. 


\title{
Study of socially constructed influences on school performance
}

\author{
Isabella Ferreira Cardoso \\ João Alberto da Silva \\ Crislaine de Anunciação Roveda
}

\begin{abstract}
The article presents a study about socially constructed influences in school performance supported by research carried out with teachers from the third years of cycle I of Elementary School. The research mainly seeks to analyze how the evaluation process is constituted with the development of students' school performance, considering the social influences that question the daily life in the classrooms and interrelate in the tasks and in the school curricular assignments. Using the methodological technique of Discursive Textual Analysis (MORAES \& GALIAZZI 2011) it was possible to arrive at two categories of analysis: pedagogical practices and inferences in school performance and socially constructed influences on school performance. The first category covers the main questions surrounding the reference to evaluative and methodological processes. The second presents reflections on family and affective issues that challenge school everyday. It is concluded that the understanding of how social extracurricular mechanisms influence the perception of students' school performance, resulting from what is presented by research on evaluation processes, occurs in a very varied and particular way of each teacher interviewed, due to the varied forms of performance and training.
\end{abstract}

Keywords: Formative Evaluation; School performance; Social influences; years of elementary school. 


\title{
Introdução
}

O presente escrito tem como intenção promover uma análise a respeito da significação dada ao processo de avaliação e pareceres efetuados no cotidiano da sala de aula, resgatando em relato de narrativas de professoras de terceiro ano de Ensino Fundamental de escolas públicas de Rio Grande/RS, as influências socialmente construídas que são interpeladas mediante esse processo avaliativo.

Tratamos como questão principal de pesquisa: como os mecanismos extracurriculares sociais apresentam-se mediante a percepção do desempenho escolar dos estudantes dos anos iniciais do Ensino Fundamental por parte dos professores? Diante dos pressupostos que norteiam essa indagação, a principal intenção é perceber que as influências, a partir do que é sugerido por professores, detém um peso de crenças construídas socialmente que, possivelmente, indicam referências exteriores da engrenagem do sistema escolar nos momentos de avaliação dos estudantes.

Consideramos a importância de estabelecer um olhar de análise, que compreenda que a classe social e os indicadores de desempenho são o ponto inicial para desenvolvimento de uma linha de raciocínio entorno do funcionamento do sistema escolar, que acaba por ser um dos principais produtores do fracasso escolar, assim como compreender a discussão no que tange aos entraves rotineiros que tem inferência no desempenho escolar de alunos, decorrente do que é apresentado por pesquisa sobre processos avaliativos no cotidiano escolar com professoras de escola pública.

Ao abordar a "denúncia da precariedade do ensino oferecido às classes populares, tanto quantitativa como qualitativamente" (PATTO, 1988, p. 73), expõe uma problemática de política pública que decorre de muitos anos de marginalização da classe social baixa em nossa sociedade, deflagrando os entraves que são circundantes em termos de melhorias e reanálise de possibilidades de mudança desse quadro que são percebidos em várias instâncias dentro do quadro de disciplinas escolares. Dessa forma, Patto (1988, p.73) declarou ainda que:

\begin{abstract}
A localização de inúmeras passagens que, embora formuladas há duas, três ou quatro décadas, continuam rigorosamente atuais na caracterização da situação do ensino elementar público, é ao mesmo tempo intrigante e aflitiva, na medida em que revela que a política educacional brasileira, pelo menos no que se refere a este nível de ensino, vem, em relação aos seus problemas fundamentais, se debatendo no beco sem saída de concepções equivocadas a respeito da natureza dos problemas e sua solução.
\end{abstract}

Para compreensão dessa linha de raciocínio, precisamos pontuar referências exteriores como decorrência de um sistema que vem década após década reproduzindo e/ou mascarando pautas que não vão, de fato, a luz do problema. 
Refletir sobre esses indicadores e atribuir a avaliação como objeto principal de análise, tendo em vista, sua extrema influência dentro dos parâmetros curriculares, permite o redirecionamento do pensamento em torno da questão central de estudo de desempenho escolar sobre influências socialmente construídas.

Por meio disso se configura como ato de extrema importância refletir, também, sobre a recorrência histórica do problema educacional brasileiro, tendo em vista que estas proposições e estes entraves até aqui anunciados são, eminentemente, construídos socialmente e tendem a inferir diretamente nas concepções dos professores no momento de avaliação provavelmente influenciado por meio dessas categorias sociais.

\section{Aprofundando a discussão}

A leitura de preconceito racial (étnico) e social trazido por Patto (1988) evidencia que no momento em que compreende que estão inter-relacionados dentro da cultura social frente a fatores econômicos e educacionais (na forma como se apresenta na sociedade brasileira) estas são, também, pautas segmentadas socialmente.

O estabelecimento de "uma relação causal entre influências negativas da cultura de grupos étnicos e sociais e o desempenho escolar" (PATTO, 1988, p. 75) demonstra como uma "teoria da carência cultural”, que fora formulada nos Estados Unidos nos anos sessenta e introduzida no Brasil na década seguinte, teve forte fator de subordinação nas ações decorrentes dessas políticas exteriores.

Quando Patto (1988) pontuou que dentro das políticas educacionais brasileira, existem há décadas, rigorosas caracterizações entorno da situação do ensino elementar público sendo estas intrigantes e aflitivas, traz em seus problemas fundamentais, o empasse que nos direciona a um beco sem saída sobre concepções equivocadas a respeito da natureza dos problemas de fracasso escolar e sua solução.

A autora identificou que a classe social é um fator que influência no desempenho escolar. Ela mostrou, em seu estudo, que a classe social é perpassada, diante das políticas educacionais, em torno da crença de "que os integrantes das classes populares são lesados do ponto de vista das habilidades perceptivas, motoras, cognitivas e intelectuais" (PATTO, 1988, p. 75), o que causa inferência nos programas de ensino direcionado a essas classes.

Mesmo sendo fundamentada há algumas décadas, a autora entende que esse modo de enxergar quem é desfavorecido socialmente e economicamente, mas sobretudo, culturalmente é repetitivo no discurso educacional, constatando que a grande problemática de fracasso escolar trata-se de um elemento que é produzido, e não apenas decorrente das falhas individuais dos alunos. 
Pautar essa incoerência fundamental do discurso educacional, nos direciona a problemática dual de ensino debatido pela já referida autora, como sendo (1) baseada em métodos reprodutivistas e de memorização, culpabilizando a formação do professor e, por outro lado, a (2) baseada no fracasso do aluno pautado em distúrbios psicológicos, físicos, em sua família ou no professor.

Outro autor que interessante neste estudo é Bernstein (1996). Ele diz que o discurso pedagógico funciona com uma gramática de responsabilização do trabalho do professor e aborda a atribuição da educação na reprodução cultural das relações de classe, indicando que a pedagogia, o currículo e a avaliação são modos de controle social.

O autor reconhece a importância de, independentemente de sua origem social, os estudantes possam agir de modo autônomo, protagonista e democrático mediante os saberes que são necessários.

Essa discussão, analisada por um viés eminentemente cultural, traz consigo um problema crucial no discurso generalista acometido em nossa sociedade, ao mesmo tempo que desvenda o preconceito frente a esse mesmo discurso. Pensando por uma perspectiva que considere as entendidas "crianças carentes" e uma escola e política educacional que abarque as classes populares, parece que, esse discurso generalista e tendencioso propagado há algumas décadas, não é apenas por meras impressões, e sim o que de fato acontece nas escolas básicas desde muito tempo e ainda nos dias atuais.

Investigar essa crença engendrada na sociedade devido a sua própria constituição histórica, põe como princípio base para questionar as professoras que lecionam nos anos iniciais, em como elas percebem a influência da classe social dos estudantes e o grande encargo disso na formação dos estudantes e em seu próprio processo de construção de conhecimento científico, social e cultural.

\section{Frustração dos desejos dos educadores e educandos}

Por meio das indagações no que se referem ao processo metodológico de pesquisa, tornou-se presente a dúvida em relação a frustração dos desejos dos educadores, principalmente ao que tange a responsabilização da produção do fracasso escolar, que a sucede em um processo mútuo de fracasso. Isso porque há dúvida referente a compreensão sobre desempenho referindo-se a defasagem no processo de aprendizagem, incluindo diante dessa questão, a pauta das variadas mudanças nos currículos formais ao longo das décadas.

Com o subsídio de Patto (1988), a prática de atribuir a frustração do desejo dos educadores à submissão das crianças a deficiências ou distúrbios psíquicos de que seriam portadoras, complementa as noções do exercício da prática de atribuir as causas de distúrbios psíquicos como o ponto dessa insatisfação vinda por parte dos professores, mas também nos 
permite subentender nesta frustração pré-conceitos estabelecidos sobre os alunos que são influências de sua classe social.

Justamente porque tudo isso vai ao encontro com a exteriorização dos problemas que deveriam ser decididos e acordados dentro dos próprios conselhos de classe e reuniões escolares, juntamente com esse corpo docente e diretivo. Passa-se assim a pensar outras alternativas de justificativa baseadas em suas falhas.

Encontramos dentro deste processo de ensino um dos dispositivos chave que orienta e ordena o mecanismo escolar que é a avaliação. Dentro do jogo avaliativo que circula entre os currículos escolares e salas de aulas, existe um tenso caminho de embate entre os desejos dos professores e os dos alunos.

Com o auxílio de Perrenoud (1999), iniciamos a análise a respeito da avaliação formativa pautando o caráter de distinção que a mesma traz e envolve os estudantes, mediante uma avaliação reguladora e taxativa habitual. Existe o entendimento de que a avaliação acaba por inferir diretamente em seu desempenho.

$\mathrm{Na}$ maior parte das turmas, alguns alunos compensam suas fracas capacidades escolares por meio de seu humor, sua camaradagem, sua coragem, seu talento esportivo. Esse equilíbrio frágil supõe que se joga um véu púdico sobre suas dificuldades propriamente escolares. Esses alunos fogem muito racionalmente - de seu ponto de vista - das situações de fracasso, em vez de encará-las. Se não tem escolha, esforçam-se mais para salvar as aparências do que para reconhecer e vencer suas dificuldades. (PERRENOUD, 1999, p. 138).

Estar a par destes contornos que são encontrados na sala de aula é ter em mente o recorrente jogo de comunicação que direciona a intencionalidade pedagógica do professor, como o redirecionamento efetuado pelo aluno que não corresponde ou não acredita corresponder com o que dele é exigido, com o que deveria ser desempenhado.

Esse caráter de excelência, que por vezes é posto aquém do que de fato ocorre nas salas de aula, só mostra o quanto o processo comunicativo é um dos fatores de maior importância para estabelecer uma relação verdadeiramente ética entre os componentes que ali se relacionam. Os sistemas escolar e relacional moldam e modificam/expressam modos de agir coletivamente que tendem a criar obstáculos situacionais que, como pontuado por Perrenoud (1999), publiciza o fracasso dos alunos e mascaram suas incompetências.

Tudo isso suscita em níveis hierárquicos de excelências que só poderia ser validada "se torna realmente interessante se dela se fala, se reputações se fazem ou desfazem, se uma imagem favorável for atribuída aos excelentes alunos" (PERRENOUD, 1999, p. 137). Esse processo corresponde majoritariamente ao papel que o professor assume e como vai comprometer esses efeitos em sala de aula. Como ele vai direcionar e pensar a sua prática para 
que o método avaliativo caminhe de forma conjunta com o que é desenvolvido por meio dos conteúdos, dos comportamentos e relações.

O cuidado dessa intencionalidade pedagógica e construção curricular é, justamente, para garantir uma proposta que permita que a comunicação se estabeleça de modo direto e honesto; que não propicie mensagens por entrelinhas e não acabe promovendo uma violência velada que rompa com a intenção formativa que esse processo carrega. $\mathrm{O}$ autor aborda que,

essa violência, a mais visível, que geralmente responde a um desvio, mascara uma outra: a obrigação escolar, a concentração de dezenas de crianças em um espaço exíguo durante horas e anos. O fato de que seja "para o bem das crianças e da sociedade" pode eventualmente justiçar essa violência; e nem por isso ela deixa de existir. (PERRENOUD, 1999, p. 140).

A compreensão de fator extracurricular como este "bem” socialmente imposto que somente o ensino impregna tão veementemente dia após dia nos campos escolares, tende a exercer uma violência extremamente simbólica e subjetiva nos alunos, por meio de uma pedagogia invisível (BERNSTEIN, 1984), que bloqueia qualquer manifestação essencialmente espontânea quando atravessada por essa obrigação escolar.

Portanto, compreender que "toda pedagogia diferenciada esbarra em desigualdades bem-instaladas e em alunos que rejeitam a escola, porque ela o rejeitou" (PERRENOUD, 1999, p. 140) é um dos pontos chaves para pensar os baixos índices de desempenho escolar, tomado pelas influências extraescolares advindas de uma frustração dos desejos dos educadores e educandos, ou seja, é inegável não pontuá-la durante esse processo de produção de fracasso escolar principalmente quando enfatizamos o caráter histórico circundante dessas constatações.

\section{Procedimentos metodológicos}

A estrutura metodológica do trabalho enquadra-se em uma pesquisa do campo qualitativo (LUDKE; ANDRÉ, 2013). A pesquisa tem base nos textos e nas narrativas respondidas pelas professoras que relatam o processo avaliativo e o cotidiano da sala de aula. A pesquisa teve como público alvo professoras do terceiro ano dos anos iniciais de Ensino Fundamental do município de Rio Grande/RS.

Os dados foram analisados por meio da técnica de Análise Textual Discursiva -ATD, auxiliando o processo de análise de pesquisa qualitativa, visando estabelecer conexões de sentidos sobre as unidades de respostas que os dados continham, entendendo como "a intenção é reconstruir conhecimentos existentes sobre os temas investigados" (MORAES \& GALIAZZI, 2011, p. 11) podendo atribuir "diversos sentidos sobre um mesmo texto" (MORAES 
\& GALIAZZI, 2011,p. 13) assim podendo potencializar o processo de compreensão que esta técnica de análise permite.

O objetivo foi o de promover uma análise concisa a respeito da significação dada ao processo de avaliação de modo que ele garantisse a compreensão de como ocorre o desenvolvimento de desempenho escolar esperado para este nível de ensino.

Foram escolhidas professoras dos terceiros anos dos anos iniciais de Ensino Fundamental, que aceitaram participar da pesquisa. Fora escolhido este ano por compreender esta como a etapa final do Ciclo de Alfabetização contemplando assim esse período final de avaliação ao qual os estudantes são submetidos.

O contato foi feito direto com as professoras e direção das escolas que aceitaram participar da pesquisa, totalizando sete professoras de cinco escolas da cidade de Rio Grande/RS. O material de pesquisa foi entregue às professoras e acertado um período de dez dias para a devolução à pesquisadora. Nele constava duas histórias ficcionais e sete questões norteadoras que contemplavam a problemática do trabalho desenvolvido; constava também uma ficha de instrução para resposta das mesmas, além de Termo de Consentimento Livre e Esclarecido (TCLE), garantindo a participação das entrevistadas e sigilo dos dados de identificação.

Teve-se como foco principal nos textos/narrativas das professoras obter conhecimento sobre suas decisões diante de propostas metodológicas abordadas em sala, tanto quanto abrir espaço para que fosse relatado experiências similares vividas das que foram descritas, por meio do contato com histórias ficcionais que exploram o tema da pesquisa.

Primeira História: Professora Maria trabalha em uma escola localizada em um bairro carente e dá aula para uma turma do segundo ano com 25 alunos regulares. Está no momento de redigir os pareceres dos alunos e ao fazer o parecer de Bianca, em suas anotações, relembra sobre sua postura em sala de aula, que passou ficar agressiva e pouco sociável. Preocupa-se apenas com a hora do lanche e recreio para jogar e brincar, mas demonstrou nas últimas atividades realizadas maior avanço na escrita e na leitura, e tem demonstrado familiaridade com os números avançando com exercícios de contagem e etc. A professora recordou, então, da tentativa de conversar com a avó da aluna que, algumas vezes, era quem estava indo buscála na escola, a respeito da sua agressividade e introspecção, e a avó não soube responder sobre o comportamento da neta. A mãe da menina também já havia resistido a essas mesmas conversas. Os únicos comentários da mãe eram a respeito das dificuldades financeiras que a família estava passando e isso estava refletindo cada vez mais na postura da criança. A professora passou a relacionar essas questões familiares em seu desempenho, e isso acabou sendo encontrado no parecer da aluna.

Segunda história: Ricardo é aluno do terceiro ano e um dos poucos de uma turma de 30 alunos que se arrisca a responder oralmente o que é solicitado pela professora Carla. No geral, Ricardo apresenta bastante familiaridade com os números e tem avançado muito nos exercícios, entretanto, está limitado até a tabuada "do 7". Por ser um aluno participativo e bastante impositivo nas sugestões de temas e atividades sugeridas pela professora, a aula tem um outro ritmo quando está presente. Mas apesar deste lado, fora da sala de aula, sem supervisão, tem arrumado muitas brigas com os colegas e volta e meia tem ido para a direção. Quando solicitado a presença dos pais, estes alegam trabalhar muito e não conseguem se fazer ISSN 2526-2882 
presente na escola, e isso tem influenciado muito no comportamento de Ricardo tanto quanto em seu rendimento nas últimas semanas. Fonte: elaborado pela autora (2018).

A maioria das questões dispostas nas histórias norteadoras suscitava instigar as entrevistadas a pensarem sobre como julgava a postura adotada pela professora frente a situação narrada. No geral, instigava pensar como e porque pensava que o desempenho seria influenciado por algum outro fator comportamental ou relacional, e em como ela trabalharia isso em aula, numa situação cotidiana.

\begin{tabular}{|c|c|}
\hline $\begin{array}{lccr}\text { Questões } & \text { para } & \text { auxiliar } & \text { e } \\
\text { reflexão/resposta da primeira história }\end{array}$ & $\begin{array}{lccr}\text { Questões } & \text { para } & \text { auxiliar } & \text { a } \\
\text { reflexão/resposta da } & \text { segunda história: }\end{array}$ \\
\hline $\begin{array}{l}\text { - Como julgas a postura adotada pela } \\
\text { professora? Comente sobre o que farias } \\
\text { e/ou se já passou por essa situação com } \\
\text { algum aluno. } \\
\text { - Em relação aos aspectos de } \\
\text { desenvolvimento cognitivo da aluna, o que } \\
\text { pode falar a respeito? } \\
\text { - O que poderia ser feito em sala de aula para } \\
\text { integrar a criança sabendo da bagagem de } \\
\text { problemas que a aluna traz de casa que } \\
\text { acarreta seu distanciamento? } \\
\text { - Como trabalharia as questões } \\
\text { comportamentais da alma? }\end{array}$ & $\begin{array}{l}\text { - Como trabalharia as questões } \\
\text { comportamentais do aluno, sabendo que } \\
\text { seu desempenho é suficiente? } \\
\text { - Acredita ser importante levar em } \\
\text { consideração seu comportamento fora da } \\
\text { sala de aula em detrimento de sua nota? } \\
\text { Argumente. } \\
\text { - Como encararia o mal relacionamento dos } \\
\text { pais com a escola/direção? O que faria para } \\
\text { efetivar uma aprocimação e diálogo? }\end{array}$ \\
\hline
\end{tabular}

Fonte: elaborado pela autora (2018).

Tais elementos nos permitem, dessa forma, pensar sobre como esse processo avaliativo está posto no cotidiano das salas de aula que, diretamente, acaba inferindo no resultado final que se estabelece como desempenho escolar dos alunos.

Utilizando-se da técnica ATD foi possível organizar o material recolhido de forma que contemplasse a questão de pesquisa, e pudesse enxergar de forma contundente as peculiaridades demonstradas nos relatos das professoras que, por vezes, foram similares em suas discussões.

A organização dos dados por meio da técnica de ATD consiste, em suma, em três grandes passos de análise. Primeiramente unitarização, pela qual foi possível selecionar unidades de sentido significativas e concernentes com a temática discutida e a proposta de pesquisa, propiciando a interpretação dos dados de modo isolado. Após isso, atribui-se códigos de identificação, palavras-chave e títulos descritivos para obter maior clareza e dados coletados.

O segundo passo, de categorização, permitiu elencar categorias às unidades selecionadas do texto em três partes: categoria inicial, categoria intermediária e categoria final 
- atribuindo, assim às unidades de sentido uma divisão por aproximação e semelhança dos dados. "É a partir delas [categorias] que se produzirão as descrições e interpretações que comporão o exercício de expressar as novas compreensões possibilitadas pela análise" (MORAES \& GALIAZZI, 2011, p. 23), tendo, portanto, na última etapa a criação do metatexto que permite a reconstrução do texto representando assim, "um esforço de explicitar a compreensão que se apresenta como produto de uma nova combinação dos elementos construídos ao longo dos passos anteriores" (MORAES \& GALIAZZI, 2011, p. 12).

O material coletado consistiu na análise de sete textos/resposta baseados em duas histórias norteadoras. Cada uma dessas histórias continha sete questões problematizadoras para que as participantes pudessem responder às questões pertinentes as suas ações frente a situações cotidianas em sala de aula, tomando como base o momento de avaliação de seus alunos.

Os textos e as questões norteadoras disponibilizados às professoras visaram compreender que, diante dessas situações, surgiriam as crenças acerca do processo avaliativo e que, de fato, poderiam ser expostos ao passo que tendem a se consolidar em suas ações cotidianas. Com o advento da utilização da ATD, o processo de unitarização permitiu a segmentação de 44 unidades de significado, e para identificação dessas unidades de sentido, a denominação foi utilizada por meio de letras "P" que significa professora, "A" à "G" que indica a quantidade de professoras entrevistadas, e as enumerações que variam de "o1" à no máximo "09" que indicam as unidades unidade de significado. Por exemplo: "PAo1" que indica uma citação do Professor A na primeira Unidade de Significado.

Após ter sido realizado esse processo de criação de unidades e sua codificação, foi possível estabelecer como categorias iniciais os temas mais recorrentes, intitulados em 12 categorias as quais expressam elementos de reflexão sobre (1) metodologia avaliativa; (2) reflexão sobre metodologia de trabalho; (3) reflexão sobre processo de aprendizagem;(4) reflexão sobre relações afetivas em sala de aula, (5) relações afetivas entre professor-aluno; abarcando ainda (6) reflexões sobre as relações familiares e sua ausência na escola, (7) sua influência nos afazeres escolares e (8) avaliação; (9) questões de comportamento, (10) desempenho escolar (11) espaço escolar e (12) registro também foram apresentadas.

Após esse processo, agruparam-se as categorias iniciais em categorias intermediárias em cinco pontos de discussão, sendo eles: avaliação; metodologia; comportamento e desempenho escolar; relações familiares; relações afetivas.

\section{Análise de dados}

Dessa forma, com o decorrer do aprofundamento da análise dos dados e interpretação das unidades de sentido, surgem as categorias finais, abordando duas temáticas: (1) práticas 
pedagógicas e as inferências no desempenho escolar e (2) influências socialmente construídas sobre desempenho escolar. Em que (1) abarca as principais questões sobre a referência a processos avaliativos e metodológicos diante do fazer escolar e da atuação docente; e que em (2) apresenta-se reflexões sobre questões familiares e afetivas que interpelam o cotidiano escolar.

\section{Práticas pedagógicas e as inferências no desempenho escolar}

A análise efetuada tem como base a concepção de avaliação formativa, trabalhada pela perspectiva de Perrenoud (1999, p. 79) que considera "no amplo sentido aqui proposto, independentemente de qualquer rótulo e de qualquer referência explicita a um modelo prescritivo, a avaliação formativa [grifos do autor] é um componente quase obrigatório de toda avaliação contínua”.

Pensar a avaliação de forma contínua é pensar as práticas pedagógicas que são realizadas em sala de aula, e "considerar como formativa [grifos do autor] toda prática de avaliação contínua que pretenda contribuir para melhorar as aprendizagens em curso, qualquer que seja o quadro e qualquer que seja a extensão concreta da diferenciação do ensino" (PERRENOUD, 1999, p. 78) considerar, também, a relação direta que isso exerce sob as inferências do desempenho escolar.

Por meio disso, entendeu-se a importância de categorizar uma parte dos dados de modo que explicitasse as práticas pedagógicas e as inferências no desempenho escolar. Foi muito recorrente o destaque das professoras sobre como ocorrem os processos avaliativos e metodológico em suas práticas: em como elas enxergam a importância de pensar sobre esse processo, e em como isso é percebido também pelos anos. Até mesmo em como as ações tomadas pelas professoras acabam, por vezes, desapercebidas por eles e em como essa dispersão tende a afetar seus comportamentos e seus desempenhos.

Interessante pensar que, das sete entrevistas, todas enfatizaram a importância do processo de avaliação, algumas destas, entretanto, acabam se diferenciando ao pensar sobre como isso influencia no desempenho dos alunos de uma forma global, ou seja, abarcando não apenas o resultado final como uma nota, mas também seu comportamento, sua postura em sala, suas relações e seu convívio em grupo.

Essa primeira categoria, portanto, abarcou as questões referentes à avaliação, metodologia, comportamento e desempenho escolar. Praticamente metade das unidades de sentido sublinharam-se neste sentido, pois encontrou-se similaridade nos relatos referentes a estas temáticas.

Mesmo em questões práticas de como abordar alguma situação em específico como as comportamentais, por exemplo, com algumas dando maior relevância a isso em detrimento 
de sua aprendizagem, no geral foi recorrente a análise sobre a forma de tratamento ao processo de aprendizagem do aluno, assim como a percepção de que o trabalho executado na sala de aula deve ser pensado articulando questões comportamentais e cognitivas.

Um ponto interessante é a ênfase a respeito das questões cognitivas desenvolvida pelos alunos, que não foi muito bem elaborada. Sendo perceptível pelo fato da decorrência da interpretação de que a pluralidade que acarreta a escola propõe diversos desafios aos professores, então percebe-se nas respostas um teor não tão aprofundado neste sentido.

Ao que compreende o processo avaliativo, uma das professoras expondo seu entendimento sobre isso, nos relata a sua impressão da seguinte forma:

Sendo o parecer uma reflexão da caminhada do estudante, é necessário que contenha com clareza e respeito todos os avanços e retrocessos e possíveis desencadeadores, buscando sempre a qualificação do processo. E sobretudo, vislumbrando novas metodologias e estratégias para auxiliar o aluno. (PAO4).

Complementando ainda que: "No meu ver o aluno não é uma nota 10 ou 5 , um conceito brilhante ou "insuficiente", é o reflexo de toda uma caminhada, de outros anos escolares, da estrutura familiar, da sua estrutura emocional. É preciso conhecer para descrever" (PAo9).

Através desses trechos, conseguimos enxergar como o processo avaliativo ocorre nas práticas executadas por ela. Muitos elementos significativos são expostos nestes dados, quando paramos para entendê-los como uma reflexão acerca das ações sobretudo didáticas que ocorrem em sala. Evidenciando que "entre o professor e o aluno, instaura-se um contrato pedagógico e didático singular em torno de tarefas particulares. Em torno do saber, de sua transmissão e de sua manifestação [...]” (PERRENOUD, 1999, p. 129) tanto quanto propostas próprias das relações causais que ocorrem em sala de aula.

Ainda sobre como pensa-se esse processo avaliativo, há também a ligação deste movimento com a família, como mostrado por este outro relato, e recorrentemente mencionado pelas entrevistadas:

"Vejo o parecer descritivo como algo que pode levar às famílias e a professora a pensar e repensar suas práticas; e a família como o vínculo afetivo mais importante nas interações sociais e a professora pensar em como, através da sua prática ela pode atingir este aluno, focando nas suas dificuldades e também nas suas potencialidades.(PCo2).

Essa resposta evidencia que "não há avaliação sem comunicação, nem, provavelmente comunicação sem uma parte de avaliação no sentido mais banal do termo" (PERRENOUD, 
1999, p. 129) e, diante disso, a comunicação com a família também é extremamente importante.

A comunicação é necessária e vai além de sala de aula, perpassa por toda comunidade escolar. Pode ser atribuída a várias questões mostrando a extrema variedade e importância destes modos de interações existentes nas salas de aula, e no ambiente escolar como um todo, não apenas nas práticas pedagógicas efetuadas pela professora, mas como as questões de aprendizagem dos alunos, as questões comportamentais, as relações com familiares, por exemplo. Isso tudo também é emergente e abordado nos relatos das professoras, como o trecho a seguir:

Percebo a escola, não apenas como um lugar que desenvolve a aprendizagem, mas um lugar principalmente de relações sociais, de interação com o outro; lugar de vivências que nos oportuniza a sabedoria e também nos possibilita crescer como pessoa, como cidadão com pensamento crítico, que luta pelos seus direitos e também cumpre com os seus deveres.(PCo7).

A colocação de OCo7 representa um modo de pensar as próprias ações que acarretam num desenvolvimento contínuo de avaliação dessas práticas. Percebe-se a intenção clara de refletir sobre uma metodologia que olhe para o aluno, que pense e repense o sentido pedagógico de suas ações.

Assim é possível ter o respaldo de Perrenoud (1999, p. 81, grifos do autor) por “de certo modo, poder-se-ia dizer que o principal instrumento de toda avaliação formativa é, e continuará sendo, o professor comprometido em uma interação com o aluno”, o que tende a promover uma efetividade neste processo, mas que ainda, também é passível de ser submetido a outras circunstâncias, principalmente por se tratar de um ambiente e relações essencialmente humanas. Então, "mesmo um modelo prescritivo de regulação deveria levar isso em conta. É o que ocorre quando se reabilita a intuição ou quando se legitima a subjetividade" (PERRENOUD, 1999, p. 81), evidenciando que mesmo diante destes processos metodológicos e práticos da ação pedagógica há a implicação de questões constituídas socialmente, e seria um equívoco deixar de pautar, principalmente, por perceber claramente na colocação das professoras, a dificuldade que elas têm de, por exemplo, "chegar nas famílias" de alunos que não apresentam um bom desempenho e comportamento. Mostra-se que o exercício deve ser outro, pensar diferentes caminhos para atingir esse(s) aluno(s), como relatado por essa professora: "O professor deve ter em mente o seu papel diante desse fato, adotando a medida de se aproximar ainda mais desse aluno, entender o que está acontecendo, para poder ajudar de forma permanente e eficaz. (PBo3).

Esta é uma realidade encontrada no cotidiano das salas de aula e imprescindível enquanto processo de reflexão e comprometimento para com o processo de aprendizagem dos 
alunos, o que acarreta numa análise muito concisa abordada por Hadji (2001) em que estabelece na avaliação formativa o caráter essencial de observação para compreender os processos evidenciados em sala de aula, além desta propor o papel dual de comunicação para com o exercício de avaliação, a qual indica ao professor os efeitos de seu trabalho pedagógico, tanto quanto comunicar aos alunos em que lugar ele está diante do que esperado pelo professor, promovendo o conhecimento de suas dificuldades, de seu desempenho de forma geral.

Nesse sentido, entender a avaliação formativa como uma utopia promissora, como denominado pelo próprio autor. Pensar que a desmistificação da avaliação promoveria muitos ganhos em vias práticas para o que ocorre em sala de aula, em que ambos os atuantes deste processo conhecem seu funcionamento e o diálogo entre ambos deveria ser claro e unidirecional.

Uma das professoras pontua algo interessante, nesse sentido, ao atrelar as questões comportamentais como um movimento de mudança de práticas para aproximar o aluno do que está sendo desenvolvido e valorizar seu desempenho de forma positiva e interativa com o grupo: "Será necessário desenvolver atividades que envolvam a participação de todos, como por exemplo, elaborar um momento para que todos possam contar ou mostrar algo que gostam de fazer, como desenhar, cantar, pintar. (PEO1).

Considerar isso é um ponto de suma importância ao que se refere na transparência do processo avaliativo e a desmistificação deste momento, justamente, porque compreende-se, muitas vezes por parte dos alunos, que o que está sendo feito por ele não é relevante, ou passou despercebido pelo professor. Como sugerido pelo autor já mencionado "para o aluno, pode ser difícil distinguir os momentos de aprendizagem e os momentos de avaliação. Dessa forma, o erro é permitido no primeiro caso e sancionado no segundo" (HADJI, 2001, p. 36).

Em suma, o que é proposto pelo autor é essencial para pautar a avaliação como uma prática a serviço das aprendizagens, e ter na pesquisa realizada um material amparador do que é pensado por professoras atuantes na área é extremamente significativo. Todos os pontos levantados até então são concernentes com o que é pensado a respeito do processo de desempenho escolar e toda a estruturação do trabalho pedagógico que deveria ocorrer na sala de aula, nas situações práticas promotoras do êxito escolar.

\section{Influências socialmente construídas sobre desempenho escolar}

Outra vertente da análise se configura na segunda categorização a qual encontra-se a recorrência de discussão em torno de questões familiares e afetivas. As questões relatam aspectos sobre a ausência da família na escola, ou sua influência nos afazeres escolares e/ou

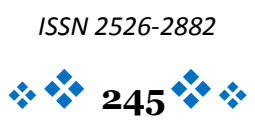


nos momentos de avaliação, seja nas relações afetivas de forma geral, entre professor-aluno, entre os alunos e seus familiares, os nos meios de interação em sala de aula.

A atribuição posta, visando discutir sobre as influências socialmente construídas sobre desempenho escolar pretende, durante o caminho, compreender e discutir outras vertentes que se encaminham para o processo de desígnio do que de fato se configura o desempenho pretendido. Este está recorrentemente ligado a uma excelência, a uma noção de sucesso que, por vezes, é exageradamente frustrante para os alunos, tanto quanto torna-se frustrante para os professores quando não compreendida como algo que ocorre dentro de sua sala de aula, com sua proposta de ensino. Isso pode ser explicitado pelo seguinte trecho: "Geralmente, os alunos são reflexos de suas vivências e expressam suas carências afetivas de maneira negativa nas socializações” (PCo6).

Devido a isso, será possível interpretar quando se trata destes reflexos de/nas socializações, que são impressões causais que foram possíveis de se observar, mas que pode ou não ter relação com o processo de aprendizagem que de fato ocorreu com o aluno, ou seja, pode garantir interferência no seu desempenho escolar.

É plausível pensar desta forma, por compreender que dentro da sala de aula, mesmo que o objetivo seja a realização plena do ensino, trata-se de um ambiente também, pleno de socialização e dentro dele ocorrem as mais variadas implicações para além de seu objetivo central, como abordado no seguinte trecho: As crianças, em sua maioria, vivenciam grandes transformações que acabam interferindo em sua aprendizagem. Acredito que a principal delas seja a falta de afetividade e atenção que acabam interferindo nas relações nesse contexto. (PBo4).

Com essa observação, é possível perceber como, novamente, os dados conversam entre si e as professoras têm uma percepção similar sobre essas situações, e acabam delineando propostas significativas de atuação que refletem nessas relações. A exemplo disso o trecho seguinte: "A melhor maneira de manter proximidade com uma criança com problemas comportamentais é o afeto. Conversar, mostrar a ela que alguém se importa com a mesma, que além do mau comportamento há qualidade, e estas devem sempre ser ressaltadas. (PGo2).

Diante disso, é interessante pensar a proposta, por vezes já mencionada, sobre fracasso escolar, que como amplamente discutida por Patto (1991) compreende-se como algo produzido socialmente. Mas, antes de tudo, é imprescindível analisar não do que se trata o "fracasso" ou o "sucesso", não de onde vem e quais variáveis são assimiladas a isso. Afinal, é possível constatar que não são as condições familiares, sociais, ambientais que promovem isso, mesmo contendo uma grande parcela de influência e, por vezes sim muito necessária de ser levada em consideração. 
Entretanto, ao que se trata de estudos dos processos avaliativos em casos específicos de desempenho defasado, nota-se problemáticas além dessas influências. O exercício de promoção de um olhar mais atento, a diferenciação de propostas metodológicas, intervenção nos processos de socialização e aproximação/convívio dos alunos/turma promove uma melhoria em seu desempenho o que tende a refletir na nota que é atribuída a esse suposto aluno com baixo desempenho em questão.

Como aborda Lahire (1997, p. 59) “a escola não é um simples lugar de aprendizagem de saberes, mas sim, e ao mesmo tempo, um lugar de aprendizagem de formas de exercício do poder e de relações com o poder". Entende-se que a escola torna-se um ambiente de intenso movimento de relações que pode ou não ser bem aceita pelos alunos, ou melhor, pode ou não ser realmente compreendidas pelos alunos como algo efetivo do funcionamento escolar.

Quando estas relações não são bem consolidadas podem acabar provocando desvios de comportamentos e até mesmo morais que tendem a suscitar problemas graves de convivência, visto que a confiança necessária não fora contemplada, como por exemplo o que é apresentado neste trecho:

"Mais do que nunca as relações familiares atravessam os fazeres escolares e mesmo buscando a parceria entre família e escola, muitas vezes, os sentimentos impotentes. Seja financeiramente, afetivamente, casos de negligência, abandono, dependências químicas, o aluno nos chega com muitas marcas e a aprendizagem certamente esbarra nesses fatores. $O$ simples fato da falta de limites interfere fortemente no processo. (PAo3).

Há impressões sobre as problemáticas provenientes da aproximação da família com a escola, mas que, quando isso não ocorre, acaba por interferir diretamente neste processo, segundo o relato desta professora.

É instigante pensar, além disso, que o exercício de poder ao qual Lahire (1997) se refere também, com um distanciamento, pode ser atrelado as implicações de poder das famílias frente ao que acontece nas escolas, quanto no comportamento dos alunos. Torna-se imprescindível, portanto, não pautar que "a coerência das disposições sociais que o ser social pode ter interiorizado depende, portanto, da coerência dos princípios de socialização aos quais foi submetido" (LAHIRE, 1997, p. 35).

O desenvolvimento deste exercício com os poderes provenientes da e na escola, num âmbito geral promove, o que Lahire (1997) também discutiu, que trata-se das figuras de um "aluno domado" até um "aluno sensato e racional". Cabe perfeitamente a discussão proposta até aqui, pois para o aluno chegar a promoção de sensatez e racionalidade é preciso o desenvolvimento de um "poder sobre si mesmo que substitui o poder exercido pelos outros e pelo exterior" (LAHIRE, 1997, p. 59). E quando isso não ocorre ou não foi promovido no seio

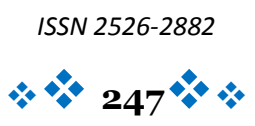


familiar, claramente, o índice de desempenho tende a diminuir tendo em vista outros critérios inegavelmente atribuídos a presença do aluno na escola.

Dentro dessa perspectiva, as noções de autonomia tanto quanto disciplina são essenciais e similares, tendo em vista o que se espera dos alunos. No caso da pesquisa realizada, entende-se com as contribuições das entrevistadas que o desenvolvimento destes deve ocorrer de forma auxiliar ao processo de aprendizagem, tanto quanto deve ser propiciada também pela família, mas o que por vezes não ocorre: "As questões comportamentais, quando a família não colabora, ficam difíceis de serem resolvidas, a professora tenta resolver junto com a equipe da escola, mas às vezes fica muito difícil. (PDo4).

Ter essa constatação deflagra o que já fora exposto anteriormente a respeito da frustração do desejo dos educadores e dos educandos, ao compreender que muitas instâncias são postas em jogo e reformulam as ações dentro da sala de aula. Ter a presença da família na escola, orientando e dialogando com o que é exercido pelos professores mediante ao desempenho dos alunos é essencial para elevar o nível de comprometimento dos alunos, para pensar o exercício autônomo e de aprendizagem de modo formativo, dialógico com o caminhar do processo de construção humana que a escola tende a desenvolver.

Dentro dessa perspectiva familiar e afetiva que permeiam as ações escolares e que muito é relatado pelas professoras na entrevista sobre como a família, muitas vezes, é distante da escola, por estar atrelado a um conjunto de fatores historicamente construídos que são e estão permeados por concepções construídas socialmente, não está posto apenas para o que os professores compreendem sobre o processo de aprendizagem e desempenho de seus alunos, mas também como a família se coloca frente ao processo parceiro de educação escolar de seus filhos, como abordado por essa professora:

As crianças vivem hoje, muitas delas, a ausência da família na escola, alguém que pergunte como foi a aula, que veja suas produções que elogie sua letra, sua leitura, seu raciocínio, que aponte o como caminhar. E a escola não supre esse esvaziamento, "de quem olhar por mim", ao contrário, expõe como um espelho. (PA07).

Pensar esse afastamento e porque ele ocorre está, em outras palavras, como relatado pela professora, fora do alcance da escola. Por isso, é necessário pensar a respeito destes entraves que ocasionam esse esvaziamento familiar que tendem a refletir no desempenho escolar dos alunos.

Quando Patto (1991, p. 178) estabelece que “a apreensão do significado do que ocorre na escola requer mais do que saber que há pessoas investidas de poder: é fundamental saber como elas exercem e por que o fazem de determinadas maneiras", cabe perfeitamente para a proposição descrita, principalmente, ao refletirmos em como todos os encargos que pode ISSN 2526-2882

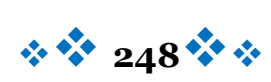


afastar um aluno ou a família como um todo da escola, pode não estar exposto no que a nota diz sobre o aluno, mas em todo o engajamento e estruturação do que a instituição escolar é e representa em nossa sociedade.

Justamente porque os entendidos casos de fracasso e baixo desempenho emergem de comportamentos e afazeres não aceitáveis, ou que não estão enquadrados diante desse processo escolar. Lahire (1987, p.19) expôs que:

\begin{abstract}
De certo modo, podemos dizer que os casos de "fracassos" escolares são casos de solidão dos alunos no universo escolar: muito pouco daquilo que interiorizam através da estrutura de coexistência familiar lhes possibilita enfrentar as regras do jogo escolar (os tipos de orientação cognitiva, os tipos de práticas de linguagem, os tipos de comportamentos... próprios à escola), as formas escolares de relações sociais.
\end{abstract}

Estar atento a isso nos possibilita compreender muito do que foi sugerido pelas professoras no decorrer das análises dos dados da pesquisa, tanto quanto a proposta de pensarse sobre o processo de desempenho escolar. Desta forma, cabe salientar a discussão também para este ponto, para expandirmos a compreensão entorno da avaliação formativa, principalmente quando não deixamos de lado o caráter eminentemente social deste processo.

\title{
Considerações finais
}

Com o aprofundar teórico e reflexão sobre a questão norteadora deste escrito é possível constatar que a percepção de desempenho escolar dos estudantes é entendida pelas professoras entrevistadas de modo muito particular e essencialmente permeado por suas próprias significações de vida e processo formativo.

Os mecanismos extracurriculares sociais são encontrados na particularidade das relações que ocorrem nas salas de aulas, que estão para além de conteúdos prescritos pragmaticamente diante do currículo pedagógico escolar.

A percepção das professoras sobre o desempenho dos estudantes está no limiar destas questões, pois é perceptível com isso que o processo de avaliação é essencial diante da significação atribuída ao exercício de aprendizagem e as práticas desenvolvidas em sala de aula, por garantir um intenso processo reflexivo por parte das professoras sobre toda a trajetória escolar dos alunos, ou o esforço máximo para pensar sobre isso, principalmente ao retornarmos ao fato de que de todas as professoras entrevistadas, de alguma forma, relataram a importância do processo de avaliação.

Entende-se que o desempenho escolar é multifacetado. Apresenta-se como uma noção muito extensa sobre vários fatores que ocorrem em sala de aula e é ordenado por cada corpo 
escolar de acordo com suas atribuições e compreensão de necessidades ao que tange o regimento escolar.

Mediante isso, a problemática em torno de um baixo desempenho pode ter influências construídas socialmente de acordo com pontos de perspectivas diferentes que estão sujeitos a muitas interpretações, principalmente ao considerarmos que diante destas concepções de processos avaliativos e formadores estão o relato de várias professoras de diferentes realidades.

Desta forma, torna-se necessário compreender o erro, os baixos desempenhos, as fragilidades tanto cognitivas quanto afetivas dos alunos como um indicativo, uma fonte de informação sobre o que passa no processo de aprendizagem e todo seu contexto. A análise do que esses índices sugerem tem correlação direta sobre o que se pensa sobre fracasso, principalmente quando os índices de fracasso são baseados, no geral, em um resultado final e taxativo como uma "única nota".

O processo de aprendizagem está para além disso, o desempenho pretendido deve ser no caminhar do processo, no dia a dia e ações práticas cotidianas propiciadas pelo professor e pelo ambiente de ensino.

Com o advento da pesquisa realizada percebe-se que muito das influências construídas está no entorno desse imaginário de escola ideal, e de um processo avaliativo regulador. Mas que, com o pensar sobre sua prática cotidiana, são evidenciados pontos muito significativos que também são levados em consideração, ou seja, há um discurso pedagógico que rege as ações na teoria do que devia ser feito, mas há um discurso pedagógico invisível que é refletido na reflexão sobre ações práticas das professoras.

A pesquisa realizada nos expõe isso de maneira muito clara, principalmente, quando questionado sobre a relação de questões cognitivas ao desempenho e comportamento dos alunos, as professoras sublinharem muito mais as questões comportamentais como as que mais pesam no decorrer da avaliação, do que as questões cognitivas propriamente ditas, mesmo tendo a compreensão de que são aspectos distintos.

Toda essa análise reflexiva advém de um capital teórico que versa sobre essas questões de modo comprometido com a excelência do desempenho escolar, e que, sobretudo, é percebido na pesquisa realizada com o desmembrar de toda as estratégias de análise de dados.

Compreendemos que as concepções e inferências de desempenho escolar são decorrentes de particularidades singulares de cada caso, cada problemática e as implicações que isso vai tendo no decorrer das atividades escolares realizadas. Contudo, as influências sociais que permeiam tais instâncias não devem ser preconizadas de pré-conceitos estabelecidos quando, justamente, cada caso resulta em problemáticas histórico-culturais que atravessam o funcionamento escolar. 


\section{Referências}

BERNSTEIN, Basil. Classes e Pedagogia: visível e invisível. Tradução: Marlene Domingos Orth e Dagmar M. L. Zibas. Cad. Pesq., n.49, p. 26-42, maio, 1984. . A estruturação do discurso pedagógico: Classes, Código e Controle. Petrópolis: Vozes, 1996.

HADJI, Charles. Avaliação desmistificada. Tradução: Patrícia C. Ramos. - Porto Alegre: Artmed, 2001.

LAHIRE, Bernard. Sucesso escolar nos meios populares: as razões do improvável. Tradução: Ramon Américo Vasques e Sonia Goldfeder. - São Paulo. Editora Ática, 1997.

LUDKE, M.; ANDRÉ, M. E. D. A. Pesquisa em educação: abordagens qualitativas. São Paulo: EPU, 2013.

MORAES, M. \& GALIAZZI, M. Análise textual discursiva. Ijuí: Ed. Unijuí, 2011.

PATTO, Maria Helena Souza. O fracasso escolar como objeto de estudo: anotações sobre as características de um discurso. Cad. Pesq., São Paulo (65): 72-77, maio, 1988.

. A produção do fracasso escolar: histórias de submissão e rebeldia. - São Paulo: T. A. Queiroz, 1991.

PERRENOUD, Philippe. Avaliação: da excelência à regulação das aprendizagens - entre duas lógicas. Tradução Patrícia Chittoni Ramos. - Porto Alegre: Artmed, 1999.

\section{Biografia Resumida}

Isabella Ferreira Cardoso. Licenciada em Pedagogia pela Universidade Federal do Rio Grande - FURG

Link do Lattes: http://lattes.cnpq.br/1650996018016019

e-mail: isabfcardoso@gmail.com

João Alberto da Silva. Pedagogo. Doutor em Educação pela Universidade Federal do Rio Grande do Sul - UFRGS. Professor da Universidade Federal do Rio Grande - FURG. Líder do Grupo de Estudos em Educação Matemática dos Anos Iniciais - GEEMAI (UFPel/FURG)

Link do Lattes: http://lattes.cnpq.br/0504077638559690 e-mail: joaosilva@furg.br 
Crislaine de Anunciação Roveda. Pedagoga. Mestre em Educação em Ciências pela Universidade Federal do Rio Grande FURG. Doutoranda pela Universidade Federal do Rio Grande - FURG. Membra do Grupo de Estudos em Educação Matemática dos Anos Iniciais - GEEMAI (UFPel/FURG).

Link do Lattes: http://lattes.cnpq.br/2242301185641803

e-mail: crislaine@furg.br 